\title{
Rijeka i oko nje kod Matoša
}

\begin{abstract}
Sorel Sanjin, Rijeka i oko nje kod Matoša (Rijeka and Suroundings in Matoš’s Work). „Poznańskie Studia Slawistyczne” 7. Poznań 2014. Publishing House Science and Innovate, pp. 211-220. ISBN 978-83-63795-79-5. ISSN 2084-3011.

The article discusses the relationship between A.G. Matoš and the city of Rijeka, which can be seen in his work „Oko Rijeke”. The focus of the analysis is in the ideology by which the discourse subject observes the city. From the viewpoint of patriotic ideology, the subject comments on the colonialist relations that occur at the time in Rijeka, but his idealization of patriotic culture, as opposed to ,negative” historic, landscape and political status of the city, impede his ability to give an accurate insight. Therefore, his work is inclined to be more political than literary.
\end{abstract}

Keywords: Antun Gustav Matoš; Rijeka; ideology; colonialism; landscape

Različite poetike kojima se Antun Gustav Matoš služio, od protoavangardne More preko impresionističkog Kipa domovine leta $188^{*}$ pa do simbolizma i poetika sna, ukazuju na kompleksnost navedena opusa koji je najobuhvatnije opisala Dubravka Oraić Tolić (2013). Tu će stilsku raznolikost primijeniti i u svojim putopisima u kojima pokazuje svu svoju modernističku, eklektičku inovativnost. O Primorju Matoš nije mnogo pisao, no ipak dovoljno da se uoče najvažniji elementi odnosa prema tom dijelu Hrvatske.

S obzirom na visok stupanj subjektivizma prisutnoga u Matoševim putopisima, treba se prisjetiti tvrdnje Helene Sablić Tomić koja je ukazala na korespondenciju putopisnih tekstova i autobiografskih žanrova (Sablić Tomić 2008: 15). Ukratko, jedinstvo se autora i pripovjedača i kod autobiografije i kod autora putopisa preklapaju. Također, ukoliko se putopis temelji na opisivanju i pripovijedanju, utoliko je riječ o fikcionalnom diskursu, 
premda je on, dijelom, u tom svojstvu upitan. Usto, postoji ugovor između čitatelja i pisca oko identificiranja „stvarnog prostora” teksta putopisa koji je moguće ovjeriti, odnosno identificirati, prepoznati.

U putopisnom tekstu okosnica je subjekt diskursa, moć opažanja i jezično oblikovanje (Duda 1998: 49). U meni zanimljivom putopisu Oko Rijeke Antun Gustav Matoš (1973b: 108-117) u svojoj putnoj prtljazi nosi ideje i uvjerenja koja Teun A. van Dijk opisuje kao ideologije (2006: 45). Ideologija kao uvjerenje „proizvod je pojedinačnog uma”, no istovremeno i društvena te kulturna dimenzija. S obzirom na to da je glavni politički aspekt Matoševa putopisa pravaštvo te da je u kontekstu njega Rijeka i promatrana, valja samo još jednom ukazati na opću činjenicu kako je navedena ideologija utjecala na brojne hrvatske književnike, pa tako i na A.G. Matoša. Dean Duda primijetit će da se u dijakronijskom slijedu najčešće provlače motivi domovine i nacije te će u tom kontekstu Matoša vidjeti vrhuncem stremljenja koje intenzivno kreće s hrvatskim romantizmom, a kulminira na prijelazu stoljeća. „U njegovim se putopisima, preko najfrekventnijih i najizravnijih motiva domoljublja i zabrinutosti za prilike u domovini, subjekt diskurza predstavlja istodobno kao brižan, ogorčen i sjetan glas gotovo posljednjega nacionalnog romantika" (Duda 1998: 119-120). No Matoš usto preuzima glas kritičara i preporoditelja koji je upućen u različite elemente nacionalnih konstituenata, kao što su povijest, kultura, vjera, psihologija itd., te je iz te perspektive svojevrsni flaner-moralizator. Kako Dubravka Oraić Tolić kazuje, Matoševi su putopisi bili ostvarenje ,jedinstva svih esteticističkih stilova umjetničke moderne" u čijem je središtu ,,ideja i estetska praksa krajolika kao prirodnoga i kulturnoga etnolika" (Oraić Tolić 2013: 322).

Naš književnik putem opisa itinerara (Zagreb-Ogulin-Plase-Rijeka) u prvi plan stavlja ideologiju otpora prema madžarskoj politici. Zbog nje su, putopiščevim riječima, Hrvati „slijepci i prosjaci”, poniženi, osramoćeni (1973b: 118). Kao i u tekstu Lijepa naša domovino gdje Rijeku zove otuđenom (1973a: 296), tako ju i u putopisu Oko Rijeke (1973b: 108-117) određuje jednostrano, detektirajući je kao mjesto koje je „bez osjećaja nacionalnog" (1973b: 111). Slično će napisati i u putopisu Slikar Crnčić, gdje će spomenuti ,tragično” sjeverno Primorje - Rijeku, Opatiju, Trsat te Grobnik (1973a: 118-125). U generalnim crtama, na prijelazu i u prvim godinama XX. stoljeća, Rijeka je mjesto koje karakterizira silovit ekonomski, ali i urbanistički razvoj te politička živost. Riječ je o razdoblju tzv. Provizorija 
(1868.-1918.), kada dvojnim/podijeljenim gradom upravlja guverner Rijeke i hrvatsko-ugarskog primorja (Anić et al. 1988: 231), kojega potvrđuje Kralj. Kako zaključuje Ferdo Šišić, ,političke prilike na Rieci bile su veoma nepovoljne po hrvatsko stanovništvo, jer građani bijahu najvećim dijelom pristaše Madžara pa su neprestanim uzbunama još 1867. uspjeli da je na Rieci učinjen kraj vlasti bana Šokčevića i imenovan (na prijedlog hrvatskoga kancelara Kuševića) kao komesar Madžar Eduard Cseh" (Šišić 2004: 468). Premda pod madžarskom upravom, Rijeka je, osobito imajući u vidu Supilov „Novi list”, mjesto aktivizma te osobito multikulturalizma. Stoga je pitanje u kolikoj mjeri Matoš u trenutku kada dolazi u Rijeku s već definiranim političkim stavom kao najznačajniji književnik moderne nastupa prosvjetiteljski, a koliko s razumijevanjem složene povijesne situacije dvojnog grada na Rječini? Dakle, koja je faktografija prisutna u navedenu Matoševu putopisu iz 11. studenoga 1909., a što bismo mogli okarakterizirati doživljajnim, emotivnim momentom, odnosno psihemskom narativnom figurom?

Štoviše, u tom nadahnutom tekstu priroda će biti u funkciji politike, karakteristični primorski pejzaž integrirat će se u ideološki kontekst, točnije u širu priču o ugarskom i talijanskom kolonijalizmu te pravaštvu. Isto će, samo rezolutnije, Matoš primijetiti u putopisu Iz Samobora u kojemu krajobrazni prostor identificira s patriotizmom ${ }^{1}$. Je li riječ o tome, kako ističe Phil Hubbard parafrazirajući Henrija Lefebvra, da prostor nije jedinstveni totalitet, nego se fragmentira u trojnu shemu opažanja, poimanja i življenja? (Hubbard 2008: 72). Značenje pojmova kao što su vidjeti, razumjeti i živjeti nije niti u teorijama identiteta homogeno polje, već je podložno različitim politikama unutar pojedinačnoga i kolektivnoga, onoga što Kaufmann naziva identifikacijskim nagodbama (Kaufmann 2006: 20). Naravno, pejzaž/krajolik reprezentacija je društvenih odnosa, stanja i potencija. Materijalna specifičnost određuje karakter ideologije (Mitchel 2008: 83). Matoš ne uspostavlja diferenciju između prirode i kulture, nego zapravo kao latourovsko „treće jamstvo” uvodi posrednika između njih - Boga, koji je vrlo proizvoljan arbitar između prirodnih zakona i društvenih ideologija (Latour 2004: 38-40). Budući da je priroda u tekstu „kržljava”, da more vonja na „praznu kutiju sardina”, da se u primorskim liticama osjeća „stisnut”,

1 ,Zato je hrvatski predio, hrvatski pejzaž isto tako važan momenat kao hrvatski narod i hrvatska prošlost. Hrvatska okolica je najbolja škola patriotizma” (Matoš 1973b: 99). 
isto se tako osjeća i unutar Rijeke koja je u društvenom, socijalnom, etičkom, ideološkom smislu „kržljava”. Prijenos prirode na naciju potpun je - Hrvat se u Rijeci osjeća „stisnuto”. Priroda je tom metaforom ništa više negoli socijalna konstrukcija, jer ukoliko je Bog arbitar između tih dvaju kompleksa, utoliko je jasnije da autor teksta vrijednost i pravo postavlja na potonju. Prošivni je bod koji uz sebe vezuje prirodu, svedenu na metaforu, ideologija (nacija, domoljublje). Za razliku od putopisa Ladanjske večeri (1911), u kojemu se kontrastira ljepota hrvatske prirode i ružnoća hrvatske društvene stvarnosti (Oraić Tolić 2013: 327), u tekstu Oko Rijeke kontrasta nema - priroda i društvo identično su negativno atribuirani, nema niti primisli o ,idiličnome prirodnome etnoliku” (Matoš 1973b: 295)².

Još je Jean-Jacques Rousseau ukazao na odnos između pejzaža i subjekta u romanu Nova Heloiza, odnosno govorio je kako se vrijednosti i karakteri emocija projiciraju u prirodu. Stav je to koji usprkos jasnim dihotomijama između prirode i kulture još uvijek ima svoju težinu. Riječima Darje Pavlič, „raskid sa antropocentričnim razumevanjem prirode po svoj prilici nije bio tako oštar da bismo ga mogli upotrebiti kao merilo za procenjivanje modernosti poezije" (Pavlič 2011: 128). Taj se stav i te kako odnosi na autorove putopisne tekstove. Matošev pripovjedni diskurs Oko Rijeke naglašeno je emotivan i senzoran, prostor i mjesto doživljava sinestezijski. Može li se uopće i pisati „topofobičan” putopis? Emotivno i estetski prihvaćajući prostor (Tuan 1977) u njegovim idealističko-sentimentalnim projekcijama radi distinkciju između opisa prostora $u$ formi oniričkog te realističnog diskursa. Dok je prvi vezan uz ono što D. Oraić Tolić naziva oniričkim krajolikom, dijeleći ga na idilu i grotesku (2012: 30), drugi je vezan uz realizam i njegova obilježja.

Tom će kompleksu suprotstaviti inače karakterističnu situaciju priobalnih gradova - gradovi kao mješovite ili odnarođene sredine, a okolica nacionalno koherentna. Matoš u putopisu spominje grobničko zaleđe, sela Grobničkog polja te nacionalnu onomastiku. Pritom neće zaboraviti napomenuti kako je Rječina kao granica između Rijeke i Sušaka zapravo i demografskog karaktera jer je Sušak pretežno slavenski. Već se i vizualno, u organizaciji prostora primjećuje limes, jer Sušak nema karakteristične gradske elemente, što indirektno priznaje i putopisac, maštajući o izgradnji još jedne luke, ovog puta u hrvatskom dijelu Rijeke. Zapravo Rijeka kao

\footnotetext{
${ }^{2}$ Kada pak govori o Grobniku, Matoš počinje idealizaciju „hrbata Hrvatstva”.
} 
podijeljeni grad ima sve elemente onoga što Zvonimir Mrkonjić podrazumijeva pod sintagmom „tragičnog viđenja svijeta” kao dijalektičkog jedinstva, mjesta koje sjedinjuje različitosti, potpunoma određeno svojim sredozemnim kontekstom (Mrkonjić 1969: 51). Još jedna od tih razlika jest gradski položaj koji mu određuje gospodarski karakter. Matoš tek okvirno apostrofira industrijski duh grada, koji ga i dandanas, kada industrije više nema, određuje, što se nikako ne može povezati niti s ugarskim niti s talijanskim aspiracijama, ali dâ $\mathrm{s}$ istim podozrivim političkim pogledom kakav je imao i ugledni flâneur koji je žanr putopisa značajno inovirao. Dodao bih niti s jugoslavenskim aspiracijama, što je iz današnje perspektive vidljivo u vrijeme Madžara u Rijeci se gradilo, a u „demokraciji” se razgrađivalo. U tom kontekstu, dok je Matoš zaokupljen povijesnim reminiscencijama, uočava tehnološki ${ }^{3}$ razvoj grada, ali mu ne pridaje nikakvu važnost, toposu koji će stoljeće i pol biti njegovim najvažnijim identitetskim mjestom.

Što nas vodi prema razlogu zbog čega to ne prihvaća kao najvažniju, industrijsku politiku svih ideologija koje su vladale Rijekom? Odgovor je jednostavan - nimalo ga ne zanima:

Inače je Rijeka bogatstvom, golemim svojim industrijama, elegancijom na Corsu i trgovinom u luci unatoč svom malom prostoru pravi velegrad prema pospanom, beamterskom, nepoduzetnom i neindustrijskom Zagrebu. Bez obilježja nacionalnog, vrijeđa Rijeka isto toliko oskudicom intelektualnog momenta u svom općem dojmu. Kao i u ostalom Primorju, avita cultura italiana nije nigdje ostavila višeg umjetničkog i kulturnog traga. Sve te bijedne latinske relikvije su ostaci Mletaka, trgovačkog grada bez dublje kulture (...). Sva talijanska kultura je na Rijeci grozan nekakav furlanski žargon, lažni politički dnevnik i kazalište gdje gostovaše švapsak opereta (Matoš 1973b: 111).

Stav je to koji vodi prema drugom aspektu putopisa, onome koji je uže politički i pravaški ${ }^{4}$.

3 Prostori su društveno proizvedeni, određuju ga načini proizvodnje, kako tvrdi Henri Lefebvre (1988: 594-600).

${ }^{4}$ U Rijeci je Pravaška stranka relativno jaka, najvažnije ime je Erazmo Barčić. I sâm je Ante Starčević u njoj živio. No riječko se pravaštvo ne odriče nekih elemenata panslavizma, a dolaskom Frana Supila u grad, razvojem „Novoga lista”, grad na Rječini ne samo da ekonomski prosperira pod madžarskom upravom, nego sve više postaje multikulturalnim središtem. 
Teza od koje polaze pravaši jest sljedeća: stvarnost Hrvatske u Habsburškoj monarhiji predstavlja apsolutno zlo, posve neodrživo stanje, a sramotna sadašnjost se uspoređuje sa slavnom prošlošću i slobodnom i sretnom budućnošću s ciljem da u pripadnika hrvatske inteligencije izazovu želju za odbacivanjem sadašnjeg stanja (Nemec 2007).

Iz ovoga se putopisa ne saznaje puno, zapravo gotovo ništa osim općih mjesta o samoj Rijeci, već jedino o prisutnom kolonijalizmu i njegovim posljedicama. To mu nije niti bila svrha. Za takvo što nije niti bilo potrebno napuštati Zagreb, situacija je u glavnom gradu na prijelazu stoljeća bila slična, kako Matoš zaključuje: „U Zagrebu već na kolodvoru prestaje Hrvatska" (1973b: 108). Do koje je mjere Matoš svjestan kako je Rijeka u poziciji kolonijalnog grada, života i sukoba doseljenoga urbanog stanovništva, Madžara i madžarona, talijanaškog te domicilnog stanovništva?

Ako za Gayatri Chakravorty Spivak tematizacija imperijalizma sadrži pitanja vezana uz carstvo, rasu i nacionalnost, onda je Rijeka u posljednjih stotinjak godina bila mjestom preklapanja dvaju velikih carstava i kultura Habsburške Monarhije te Italije. Stoga za razumijevanje riječkog identiteta - za Gabrielea D'Annunzija Rijeka je bila obećana zemlja - podrazumijeva poznavanje njezine povijesti i geografije. Borba za vlastiti jezik nije samo pitanje identiteta, premda je fundamentalna, ona u sebi sadrži i načine na koji se svijet društveno, kulturno, politički i ekonomski organizira. O sustavu proizvodnje i načinima komunikacije uvelike ovisi i rasprostranjenost nekog jezika. Tisak je kao takav u Europi bio smrt za male jezike (Chatterjee 1995: 164). U Rijeci je s obzirom na broj stanovnika bilo neobično puno novina na talijanskom jeziku te institucija koje sustavno rade na memoriji grada ${ }^{5}$. Matošev je pristup identitetu esencijalistički, prirodno i povijesno pravo nacionalnom kompleksu suprotstavlja kolonijalističkim praksama $\mathrm{s}$ obzirom na to da potonje nisu imale politiku priznavanja djelatnom

${ }^{5}$ Krajem osamdesetih godina XIX. st. osniva se Società di Storia Patria s ciljem brige oko riječkih spomenika, muzeja i arhiva kojoj je namjera reafirmacija antičkih (rimskih talijanskih) obilježja, u iredentističkom duhu osniva se društvo Deputazione fiumana di storia patria itd., ukidaju se sedamdesetih godina XIX. st. hrvatske škole, a na razini grada osnivaju talijanske (madžarske su državne). Tek se osnivanjem hrvatskoga političkog (pravaškog) glasila „Sloboda” (1878-1883) donekle jezična i kulturna politika počela oslobađati u smjeru nacionalne afirmacije (Anić 1988: 269-273). 
kategorijom. Stoga identitetska ontologija ,proizlazi iz dubinski strukturirane i tradicijom nataložene svijesti o individualnom jastvu, kolektivnoj pripadnosti i granicama na koje nas ta pripadnost obvezuje" (Kalanj 2010: 119) i kao takva zauzima obrambeni $\operatorname{stav}^{6}$. Zapravo su se u Rijeci kroz njezinu graničnu povijest događali procesi inducirane multikulturalnosti do onog trenutka kada je politika multikulturalizma kao nova faza modernosti (Kalanj 2010: 130) koja nadilazi prosvjetiteljske kanone postala njezinim osnovnim identitetskim obilježjem.

Treći aspekt vezan je uz Baštinu, prvenstveno književnu i uže povijesnu, u nekim dijelovima korespondentnu i s mitom. Matoš uspostavlja vezu između zajednice i priče kao mita (Latour 2004: 91). Štoviše, njegova je funkcija kao pisca, usprkos impresionističkom prosedeu, odabrati ona mjesta književno-kulturne i opće povijesti kontekstualno prepoznatljive kako bi mogla biti „ispravno” dekodirana. Matoš odabire vrijednosne arhetipove koji se u svojim značenjima vezuju uz integraciju nacionalnog prostora, povijesti i baštine. „Mitovi daju odgovore na nepoznanice o svetu koja predstavljaju izvor frustracije za čoveka, usled njegove nemoći da njima realno ovlada. Mitovi su kulturna nužnost jer donose imaginarnu satisfakciju i tako uspostavljaju ravnotežu smisla" (Kovačević 2006: 9). Imaginarni elementi mita Matošu omogućavaju bogatu literarizaciju, shodno tome i zavođenje. U nekim svojim tekstovima vezanima uz Rijeku Matoš inzistira na nacionalno-političkim idejama te pritom zanemaruje svoju izuzetnu estetsku kompetenciju. Tako će pučki pjesnik Ivo Grohovac Riječanin za Matoša, samim tim što je ,izdao u patriotskom duhu spjevane Glasove sa Kvarnera, pune stare pravaške poezije" (Matoš 1973c: 113), biti paradigma preporoditelja. Na stranu to što je i u svoje vrijeme Grohovac minoran književnik, danas tek književnopovijesna činjenica. U jednom će ga drugom tekstu, povodom zbirke pjesama istog književnika Rijekom i Rešćinom (1912) (Matoš 1973c: 238-240), također usporediti s Ilircima i pravašima, a sve kako bi hrvatskoj svijesti i misli, ,sposobnosti i duševnoj plemenitosti našega naroda" (Matoš 1973c: 239) u Rijeci osigurao simbolički kapital oko kojega se može identificirati. Štoviše, u tom će gorljivom pamfletu Matoš pjesničku tehniku Vladimira Nazora nazvati aljkavom za razliku od Grohovčeve okretnosti i lakoće, kontrastirat će visoku kulturu i onu gotovo

${ }^{6}$ Taj će stav nakon 1945. rezultirati velikim egzilom talijanskog stanovništva. 
pa pučku. Iz književnopovijesne vizure sasvim je očita pogrešna Matoševa atribucija riječkog ,,pravaškoga pjesnika”. Matošu je zbog nacionalne komponente mit dragocjeniji od mišljenja povjesničara u vezi s toliko eksploatiranom bitkom protiv Tatara na Grobničkom polju koja se nije niti dogodila, tako kaže: ,a ma šta rekli historičari, vjerojatno je da su naši oci na tom polju smrvili Tatare, jer je puno ovih imena" (1973b: 115). Transcendentalni karakter mitskih sadržaja idealan je Matošu kako bi esencijalistička pitanja postavio u fokus književnosti, imajući na umu kako se njime usto bavi i religija. Ukoliko je mit metaforička priča, utoliko mu je književni diskurs prirodno mjesto prikazivanja. Mit i ideologija imaju dodirnih točaka jer ,djeluju u području nesvjesnoga” (Nöth 2004: 415).

Matoš u putopisu često, vrlo znakovito, spominje Zrinske i Frankopane. Ne samo da se oni nalaze kao povijesno-mitske ličnosti, nego se putem njih i njihova grada Grobnika pravaštvo detektira kao ona etička komponenta koja određuje i književnost i politiku. Matoš se ne uspijeva othrvati moraliziranju, pače u tu svrhu iskorištava onodobni pravaški ideološki folklor koji je Krešimir Nemec nazvao kultom Zrinskih i Frankopana (Nemec 2007: 9-12). Sve zbog toga što je pripovjedač ogorčen kolonijalnim diskursom koji vlada Rijekom. Poetički mu pak kao opravdanje služi romantizam sa svojim isticanjem povijesnih paradigmi kao toposima idealizma u kojemu je mit jedno od konstitutivnih uporišta.

Sasvim je razumljiva pozicija A.G. Matoša, u konačnici, kao književnika koji je razmišljao integrativno, poetički i politički, premda u prvom smislu kreativno, u drugom pomalo zaslijepljeno. Prihvaćajući ideju domoljublja u smislu aksioma, prihvatio je i suženi pogled koji mu je onemogućio da vidi razlike u bitnim elementima života gradova, u ovom slučaju Rijeke koja je po mnogočemu bitno drukčija od svih ostalih hrvatskih gradova. Osobito povijesno i gospodarski, ali i juridički, kulturno, jezično, a time i mentalitetno. Po svemu sudeći jučer, danas, sutra.

\section{Literatura}

Anić V. et al., 1988, Povijest Rijeke, Rijeka.

Chatterjee P., 1995, Nationalism as a Problem, u: The Post-colonial Studies Reader, ur. B. Ashcroft, G. Griffiths, H. Tiffin, Routledge, str. 164-166. 
van Dijk T.A., 2006, Ideologija, prev. Ž. Filippi, Zagreb.

Duda D., 1998, Priča i putovanje. Hrvatski romantičarski putopis kao pripovjedni žanr, Zagreb.

Hubbard P., 2008, Prostor/mjesto, u: Kulturna geografija - kritički rječnik ključnih pojmova, ur. D. Atkinson, P. Jackson, D. Sibley, W. Washbourne, prev. D. Lalović, Zagreb, str. 71-79.

Kalanj R., 2010, Hrvatski nacionalni identitet u globalizirajućem svijetu, Zagreb.

Kaufmann J.C., 2006, Iznalaženje sebe. Jedna teorija identiteta, prev. M. Gregorić, Zagreb.

Kovačević I., 2006, Mit i umetnost, Beograd.

Latour B., 2004, Nikada nismo bili moderni. Ogled iz simetrične antropologije, prev. J. Milinković, Zagreb.

Lefebvre H., 1988, Kritika svakidašnjeg života, prev. P. Vranicki, Zagreb.

Matoš A.G., 1973a, Iz Samobora, u: Sabrana djela, sv. 4, Vidici i putovi. Naši ljudi i krajevi, ur. D. Tadijanović, Zagreb, str. 97-107.

Matoš A.G., 1973b, Oko Rijeke, u: Sabrana djela, sv. 4, Vidici i putovi. Naši ljudi i krajevi, ur. D. Tadijanović, Zagreb, str. 108-117.

Matoš A.G., 1973c, Pjesme I. Grohovca Riječanina, u: Sabrana djela, sv. 7, O hrvatskoj knijževnosti II, ur. D. Jelčić, Zagreb, str. 238-240.

Mitchel D., 2008, Krajolik, u: Kulturna geografija. Kritički rječnik ključnih pojmova, ur. D. Atkinson, P. Jackson, D. Sibley, N. Washbourne, prev. D. Lalović, Zagreb, str. 81-90.

Mrkonjić Z., 1969, Vaga tragičnog, „Vidik” br. 9-10, str. 46-52.

Nemec K., 2007, Pravaštvo i hrvatska književnost, <www.hrvatskiplus.org>, 25.11.2013.

Nöth W., 2004, Priručnik semiotike, prev. A. Stamać, Zagreb.

Oraić Tolić D., 2012, Matoševa poetika sna, u: Prostori snova. Oniričko kao poetološki $i$ antropološki problem, ur. Ž. Benčić, D. Fališevac, Zagreb, str. 310-338.

Oraić Tolić D., 2013, Čitanja Matoša, Zagreb.

Pavlič D., 2011, Lirski subjekt i prostor (poređenje tradicionalne i moderne lirike), „Polja" br. 471, str. 126-31.

Sablić Tomić H., 2008, Hrvatska autobiografska proza, Zagreb.

Šišić F., 2004, Povijest Hrvata. Pregled povijesti hrvatskoga naroda II, Split.

Tuan Y-F., 1977, Space and Place. The Perspective of Experience, Minneapolis. 
